\title{
Analisis Kelayakan Usaha Street Food Untuk Pemanfaatan Lahan Parkir Pasar Modern
}

\author{
Rangga Herbowo Putra1, Endang Chumaidiyah², Meldi Rendra ${ }^{3}$ \\ Program S1 Teknik Industri, Fakultas Rekayasa Industri, Universitas Telkom ${ }^{1}$ \\ Program S1 Teknik Industri, Fakultas Rekayasa Industri, Universitas Telkom² \\ Program S1 Teknik Industri, Fakultas Rekayasa Industri, Universitas Telkom ${ }^{3}$
}

\begin{abstract}
The street food area of Modern Market Goldland, Karawaci is an area that is provided for buying and selling activities among small and medium enterprises with consumers. Declining interest of the public to visit the shopping center as a result of their online shopping site makes one of the reasons why street food area began to develop, other than that street food festival can also help promote micro-economy of a country itself. This study aimed to determine whether land rental business street food is already feasible in terms of aspects of the market, technical, and financial aspects. Analysis of market aspects are used to determine potential markets, available markets and target markets. After collecting market data by distributing questionnaires, the potential market percentage is $94 \%$, the available market is $97 \%$ of the potential market, and the target market is $5 \%$ of the available market. Analysis of technical aspects was carried out to see the outcome and income that occurred in the street food rental business in the next 5 years. The results of the calculation of financial aspects, obtained the value of NPV (Net Present Value) of Rp. 95,516,306, the value of IRR (Internal Rate of Return) of 27.67\% and PBP (Pay Back Period) of 4.2 years. Because the IRR value is greater than the MARR value that is $11.74 \%$ and the NPV value is greater than 0 , then the land leasing business by utilizing the street food market laha Modern Goldlan, Karawaci is said to be feasible.
\end{abstract}

Key Words. Feasibility Study, Street Food, NPV, IRR, PBP

Abstrak. Kawasan street food Pasar Modern Goldland, Karawaci merupakan kawasan yang disediakan untuk kegiatan jual beli antar para pedagang kecil dan menengah dengan konsumen. Menurunnya minat masyarakat untuk mengunjungi pusat perbelanjaan akibat adanya situs belanja online menjadikan salah satu penyebab mengapa kawasan street food mulai digemari, selain itu kawasan street food juga dapat membantu memajukan ekonomi mikro sebuah negara. Penelitian ini bertujuan untuk mengetahui apakah bisnis penyewaan lahan street food ini sudah layak untuk dijalankan ditinjau dari aspek pasar, aspek teknis, dan aspek finansial. Analisis aspek pasar digunakan untuk menentukan pasar potensial, pasar tersedia dan pasar sasaran. Setelah mengumpulkan data pasar dengan penyebaran kuesioner, didapatkan persentase pasar potensial yaitu sebesar 94\%, pasar tersedia sebesar $97 \%$ dari pasar potensial, dan pasar sasaran sebesar $5 \%$ dari pasar tersedia. Analisis aspek teknis dilakukan untuk melihat pengeluaran dan pemasukkan yang terjadi didalam bisnis penyewaan lahan street food dengan memanfaatkan lahan parkir pasar modern ini dalam 5 tahun yang akan datang. Hasil dari perhitungan aspek finansial, didapatkan nilai NPV(Net Present Value) sebesar Rp 95.516.306, nilai IRR(Internal Rate of Return) sebesar 27,67\% dan nilai PBP(Pay Back Period) sebesar 4,2 tahun. Dikarenakan nilai IRR lebih besar dari nilai MARR yaitu $11,74 \%$ dan nilai NPV lebih besar dari 0, maka bisnis penyewaan lahan street food dengan memanfaatkan laha pasar Modern Goldlan, Karawaci ini dikatakan layak untuk dijalankan.

Kata Kunci : Analisis Kelayakan, Street Food, NPV, IRR, PBP

Correspondence. Email ${ }^{1}$ ranggata12@gmail.com, ${ }^{2}$ endangchumaidiyah@yahoo.co.id,

33meldirendra@telkomuniversity.ac.id

History of article. Received: April 2019, Revision: Juli 2019, Published: September 2019

\section{PENDAHULUAN}

Sejak jaman dulu wisata pasar malam memang sudah menjadi salah satu destinasi wisata banyak masyarakat, berbagai macam jasa dan produk diperjual belikan, tidak hanya di Indonesia,fenomena pasar malam ini juga ada di negara-negara asia tenggara lainnya. Hal ini berhubungan dengan suhu udara di negara- 
negara tropis yang relative tidak begitu dingin seperti layaknya di Eropa atau negara bagian barat lainnya. Namun pada tahun 90 -an keatas keberadaan pasar malam mulai tegusur oleh banyak pusat-pusat perbelanjaan yang terletak di perkotaan. Namun dewasa ini keberadaa street food mulai diperhitungkan, Street food merupakan salah satu bentuk invoasi dari pasar malam yang lebih memfokuskan segmentasi untuk menjual makanan baik itu makanan berat maupun makanan ringan untuk langsung di konsumsi di tempat. Kalangan remaja menjadi target utama dibangunnya usaha Street Food ini,karena selain menjadi tempat untuk menyantap makanan, street food juga mulai memiliki fungsi lain seperti dijadikan sebagai tempat rekreasi kuliner,titik pertemuan bahkan street food mulai menggantikan posisi Cafe untuk kalangan remaja, biasanya bekumpul. Menurut tabel dibawah jumlah populasi usia 16-30 tahun di perkotaan memiliki jumlah yang cukup banyak yaitu $25,22 \%$ dari total keseluruhan populasi. Dengan menargetkan konsumen dan tenant dari kalangan remaja dan usia produktive tentunya usaha street food ini dapat menjadi usaha yang menjanjikan.

\begin{tabular}{|c|c|c|c|c|}
\hline $\begin{array}{l}\text { Karakteristik } \\
\text { Demografi }\end{array}$ & $<16$ tahun & $\begin{array}{l}16-30 \\
\text { tahun }\end{array}$ & $>30$ tahun & Total \\
\hline Total & $28,81 \%$ & $24,27 \%$ & $46,92 \%$ & $100,00 \%$ \\
\hline \multicolumn{5}{|l|}{ Tipe Daerah } \\
\hline Perkotaan & $27,92 \%$ & $25,22 \%$ & $46,87 \%$ & $100,00 \%$ \\
\hline Perdesaan & $29,82 \%$ & $23,19 \%$ & $46,98 \%$ & $100,00 \%$ \\
\hline \multicolumn{5}{|l|}{ Jenis Kelamin } \\
\hline Laki-laki & $29,37 \%$ & $24,43 \%$ & $46,20 \%$ & $100,00 \%$ \\
\hline Perempuan & $28,25 \%$ & $24,10 \%$ & $47,65 \%$ & $100,00 \%$ \\
\hline
\end{tabular}

Tabel 1.1 Persentase Penduduk Menurut Kelompok Umur, 2017

Dari pemaparan permasalahan diatas banyak orang yang mengambil jalan pintas, lahan-lahan ilegal dipinggiran jalan pun menjadi solusi sementara untuk mereka yang ingin memulai merintis usaha, tanpa memikirkan dampak-dampak yang ditimbulkan dalam jangka waktu panjang. Berdasarkan hasil observasi penulis, lahan street food menjadi lahan yang cukup diminati oleh para pengusaha start up dikarenakan harga sewanya yang relative murah dan dapat menampung puluhan pedagang/tenan, dengan harga sewa yang murah yaitu sekitar Rp 1.500.000 sampai Rp 3.000.000 per bulan dan harga jual yang tidak jauh beda dengan harga jual makanan di pusat-pusat perbelanjaan tentunya akan menghasilkan omset yang cukup besar pula mengingat tenan tidak terbebani dengan biaya sewa lahan yang mahal,tercatat bedasarkan hasil observasi penulis setidaknya satu gerai atau tenan mendapatkan omset sekitar Rp 500.000 - Rp 5.000 .000 per harinya. Melalu penelitian ini penulis bertunjuan untuk lebih memperhatikan usaha kecil dan menengah,terlebih memingat sektor usaha kecil \& menengah merupakan sektor dengan perputaran uang yang cukup besar. Karena kedepannya penulis memperkirakan bahwa keberadaan pusat perbelanjaan akan tergususur dengan perkembangan zaman dan dengan tergusurnya pusat perbelanjaan tergusur pula komoditikomoditi yang ada di dalamnya, tidak terkecuali adalah rumah-rumah makan.

\section{KERANGKA PENELITIAN \& HIPOTESIS}

2.1 Pengertian Studi Kelayakan

Menurut Kasmir dan Jakfar (2003),yang dimaksud dengan Analisis Kelayakan Bisnis merupakan suatu kegiatan yang mempelajari sarana mendalam tentang suatu kegiatan atau usaha yang akan dijalankan, untuk menentukan layak atau tidaknya suatu bisnis dijalankan.

\subsection{Aspek Pasar}

Aspek pasar menjadi aspek yang bisa dikatakan paling diutamakan dalam studi kelayakan usaha, hal ini dikarenakan aspek pasar memegang peranan penting terkait produk atau jasa yang akan kita jual. Aspek ini nantinya yang akan berperan untuk menentukan rencana investasi dikarenakan untuk melihat jumlah maupun jenis pasar yang akan menyerap hasil produk atau jasa yang kita buat, meskipun begitu aspek pasar juga bergantung terhadap aspek-aspek lain seperti misalnya aspek teknis, bila nantinya ketika ditinjau melalui aspek teknis tidak mampu menghasilkan produk tersebut maka akan berimbas pula ke aspek pasar, demikian pula sebaliknya. Pada aspek pasar ini terdiri menjadi tiga bagian, antara lain.

1. Pasar tersedia

2. Pasar sasaran 


\section{Pasar potensial.}

Pada aspek ini nantinya akan diteliti seberapa besar pasar potensial dan pasar tersedia dari pendirian usaha street food. Pasar potensial membantu kami untuk membagi pasar menjadi cakupan cakupan besar yang kemungkinan akan tertarik dengan jasa kami,pasar tersedia membantu kami mendefinisikan kebutuhan konsumen menjadi lebih jela. Penelitian yang kami lakukan yaitu dengan mengumpulkan data dan informasi dari berbagai sumber baik itu dari pihak pengelola maupun pihak penyewa. Ketiga hal tersebut merupakan bagian dari aspek pasar yang nantinya penulis akan dapat melihat estimasi permintaan dan pendapatan yang akan diperoleh dan akan dipergunakan untuk perhitungan aspek finansial.

\subsection{Aspek Teknis}

Aspek Teknis adalah aspek yang berkaitan dengan pembangunan usaha secara teknis dan operasionalnya yang meliputi deskripsi produk, penentuan kapasitas produksi, ekonomis, proses produksi yang dilakukan, persedsiaan bahan baku, jumlah tenaga kerja, penggunaan mesin dan peralatan. Selain itu juga berfokus kepada lokasi dan tata letak usaha itu didirikan ditinjau bersadarkan bermacam-macam aspek, biasanya dibedakan menjadi dua aspek antara lain aspek kuantitatif dan aspek kualitatif.

Ada beberapa langkah untuk mengoptimalkan penggunaan lahan dan mengatur tata letak agar lebih efektif dan efisien, antara lain menentukan jumlah mesin atau peralatan yang dibutuhkan secara tepat guna, mengukur luas bidang usaha secara keseluruhan, mengukur dimensi dari masing masing alat maupun luas yang diperlukan, membuat rancangan awal terkait penempatan mesin mauapunn peralatan, dll. Teknik dalam memilih perlatan yang sesuai dengan. Pada aspek ini akan diteliti seberapa besar dan apa saja sumber daya yang kita butuhkan untuk menjalankan bisnis ini, lokasi yang strategis untuk menjalankan bisnis ini baik itu dari segi harga maupun dari segi daya tarik konsumen, dibuat pula layout atau rancangannya, menentukan jumlah pegawai yang dibutuhkan beserta cakupan kerja mereka masing-masing, serta sistem atau prosedur operasional yang dibuat baik itu untuk penyewaan maupun pembayaran. Beberapa hal tersebut diteliti agar sebuah bisnis dapat berjalan lebih optimal.

\subsection{Aspek Finansial}

Pada aspek Finansial penelitian mencakup berapa banyak biaya inisiasi, biaya operasional dan biaya maintenance yang dibutuhkan, perhitungan yang dilakukan mengacu kepada penelitian mengenai aspek pasar dan teknis yang sebelumnya sudah terlebih dahulu diteliti, perhitungan yang akan dilkaukan meliputi.

1. Aktiva Tetap

Biaya sewa gedung dan lahan, perlengkapan dan lain-lain.

2. Aktiva tetap tak berwujud

Biaya pendahuluan bisnis seperti biaya survei pasar, laporan studi kelayakan, dan lain-lain.

3. Net Present Value

Menurut James C Van Home (2004) NPV adalah perhitun nilai saat ini berdasarkan arus kas bersih investasi dikurangi dengan arus keluar kas awal. Singkatnya NPV adalah metode untuk mengetahui apakah pendapatan yang dihasilkan selama jangka waktu tertentu dapat menutup biaya investasi yang sebelumnya sudah dikeluarkan. Adapun rumus yang berlaku untuk menghitung NPV, antara lain :

$$
N P V=\sum_{t=1}^{n} \frac{C F t}{(1+K)^{t}}-I_{0}
$$

Keterangan:

$\mathrm{CFt}=$ Aliran Kas bersih tahun $\mathrm{t}$

lo $=$ Investasi awal pada tahun 0

$\mathrm{K}=$ Suku Bungan (Discount Rate)

4. Interst Rate of Return

Menurut Umar (2005) IRR adalah cara yang digunakan untuk mencari tingkat suku bunga yang menyamakan nilai sekarang dari arus kas yang diharapkan di masa mendatang, atau penerimaan kas, dengan mengeluarkan investasi awal. Apabila IRR sama dengan tingkat discount maka usaha tidak dapat mendapatkan untung atau rugi, tetapi jika IRR lebih kecil dari tingkat discount rate maka usaha tersebut tidak layak diusahakan, sedangkan apabila IRR lebih besar dibanding tingkat discount rate maka usaha tersebut dapat dinyatakan layak untuk diusahakan. Adapun rumus yang berlaku untuk mencari IRR adalah sebagai berikut : 


$$
0=\sum_{t=0}^{n} \frac{\text { Cash Flow }}{(1+r)^{t}}
$$

Keterangan :

$\mathrm{n}$ : perode terakhir di mana cash flow diharapkan

$r$ : tingkat bunga yang akan menjadikan PV dari kas bersih sama dengan present value

5. Payback Period.

Payback Period adalah jangka waktu yang dibutuhkan untuk mengembalikan pengeluaran pada fase investasi dengan menggunakan aliran kas yang diterima (Drs.Sutrisno, MM, 2007). Menurut Husein Umar (2007) Payback Period adalah Suatu periode yang dibutuhkan untuk menutup kembali pengeluaran investasi dengan menggunakan aliran cash. James C Van Horne (2004) Periode Pengembalian merupakan pepriode waktu yang diminta untuk arus kas kumulatif yang diharapkan dari proyek investasi sehingga sama dengan arus keluar kas awal. Dari pemaparan diatas dapat penulis tarik kesimpulan bahwa Payback Period adalah Periode waktu dimana aliran kas dibutuhkan untuk menutup atau mengembalikan pengeluaran yang dikeluarkan untuk biaya investasi. Adapun rumus yang berlaku dalam menghitung payback period adalah :

$$
\begin{aligned}
& \text { 6. } \mathrm{PP}=\frac{\text { INVESTASI }}{\text { KTAS BERSIH TAHUN BERSANGKUTAN }} \times \\
& \text { Tahun }
\end{aligned}
$$

\section{Benefit Cost Ratio}

Menurut James C Van Horne (2004) Profitability Index adalah rasio nilai kas bersih saat ini terhadap arus kas keluar awal (Investasi). Metode ini disebut juga dengan cost benefit analysis method. Berbeda dari NPV, jika NPV merupakan hasil dari selisih antara aliran kas bersih dengan besarnya investasi awal, PI atau Profitabilitas Index merupakan perbandingan antara aliran kas bersih dengan besarnya biaya investasi awal yang ditampilkan dalam bentuk persentase. Berikut merupakan rumus untuk mencari besarnya Profitabilitas Indeks sebuah usaha, antara lain sebagai berikut :

$$
P I=\frac{\sum P V \text { Kas Bersih }}{\sum \text { Investasi }} X 100 \%
$$

Berdasarkan perhitungan tersebut nantinya akan menunjukan apakah pendirian sebuah bisnis atau usaha tersebut layak atau tidak.

\section{METODE PENELITIAN}

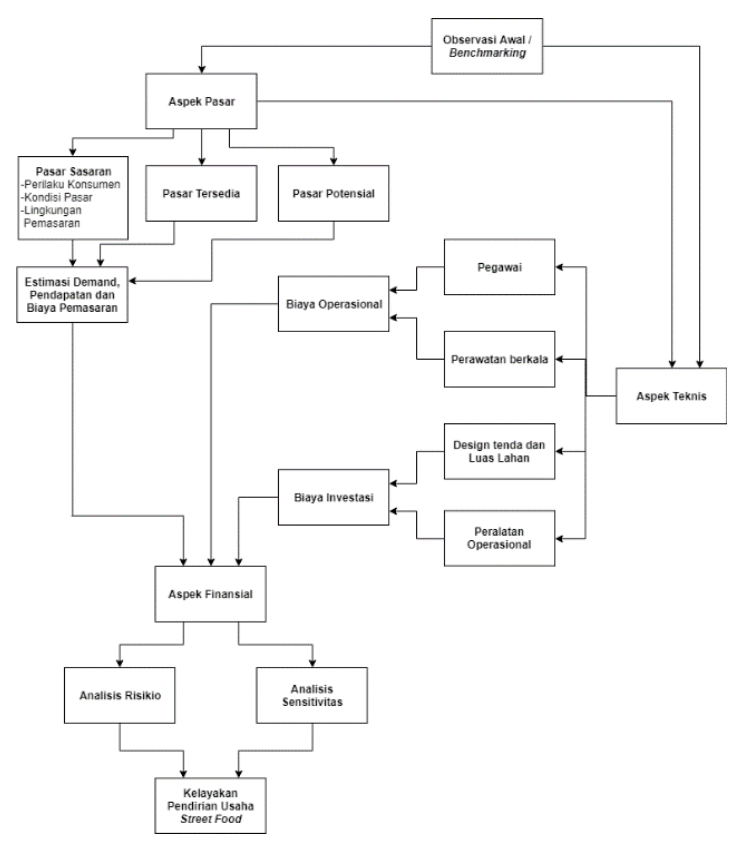

Gambar 3. 1 Model Konseptual

Tahap identifikasi masalah merupakan tahapan awal dimana sebuah objek diteliti lebih lanjut mengenai segala permasalahan maupun penghambat dalam proses bisnisnya. Tahap identifikasi ini juga memaparkan mengenai perumusan masalah berdasarkan latar belakang dan studi literatur yang dilakukan.

Tahap kedua adalah Pengumpulan data dilakukan untuk memperoleh informasi atau data-data terkait yang dibutuhkan guna mencapai tujuan penelitian. Menurut (Sugiono, 2002) ada 3 metode yang dilakukan untuk mengumpulkan informasi dan data-data terkait, yaitu.

1. Metode Observasi

2. Metode wawancara

3. Metode Kuesioner

Tahap ketiga adalah pengolahan data dimana pada tahapan ini data-data yang sebelumnya telah didapat dari hasil observasi dan wawancara baik itu data aspek pasar, aspek teknis, dan aspek finansial nantinya akan direkap dan diolah menggunakan rumus yang diperoleh dari studi 
literatur. Data-data yang diolah tersebut akan menghasilkan informasi yang digunakkan untuk mencapai tujuan penelitian.

Tahap terakhir, data biaya inisiasi dan modal awal yang sebelumnya telah didapat dan telah diolah dengan metode $N P V, I R R, P B P$ dan sebagainya akan diselaraskan dengan struktur pembiayaan dan studi literatur sehingga dapat terlihat apakah usaha street food ini dapat terlihat layak atau tidak.

\section{HASIL DAN PEMBAHASAN}

1. Aspek Pasar

Data yang sebelumnya telah dikumpulkan melalu penyebaran kuisioner, lalu diolah untuk mendapat 3 jenis pasar antaralain :

a. Pasar Potensial

Pasar potensial merupaka jumlah pasar yang memiliki minat terhadap produk atau jasa yang ditawarkan, berdasarkan hasil pengolahan data kuesioner persentase responden yang memiliki minat terhadap jasa penyewaan lapak street food ini sebesar $94 \%$.

b. Pasar tersedia

Pasar tersedia merupaka jumlah pasar yang memiliki minat dan kemampuan untuk membeli produk atau jasa yang ditawarkan, berdasarkan hasil pengolahan data kuesioner persentase responden yang memiliki minat dan kemampuan terhadap jasa penyewaan lapak street food ini sebesar $97 \%$.

c. Pasar Sasaran

Pasar sasaran merupaka jumlah pasar yang dijadikan sasaran oleh pemilik jasa atau produk, pasar ssasaran merupakan bagian dari konsumen yang memiliki minat dan kemampuan terhadap produk atau jasa yang ditawarkan, berdasarkan hasil pengolahan, berdasarkan pertimbangan perusahaan didapatkan pasar sasaran sebesar $5 \%$.

\section{Aspek Teknis}

Data yang digunakan pada aspek teknis ini adalah data hasil benchmarking, observer dan wawancara. Data-data aspek teknis terdiri dari, proses operasional, jumlah tenaga kerja yang dibutuhkan, peralatan dan fasilitas yang dibutuhkan. erdasarkan data-data tersebut didapat biaya investasi yang dibutuhkan untuk menjalankan bisnis kawasan street food ini yaitu berjumlah Rp 78.397.250, biaya siup sebesar Rp 2.700.000 dan working capital sebesar $\mathrm{Rp}$ 134.775.143.

Tabel 1 Kebutuhan Dana

\begin{tabular}{|l|l|}
\hline \multicolumn{2}{|l|}{ KEBUTUHAN DANA } \\
\hline $\begin{array}{l}\text { Total Project Cost (TPC) } \\
2019\end{array}$ & Total \\
\hline Investasi tetap & $\begin{array}{l}\mathrm{Rp} \\
78.397 .250\end{array}$ \\
\hline $\begin{array}{l}\text { Working capital } \\
\text { (perkiraan biaya selama } \\
\text { periode 3 bulan) }\end{array}$ & $\mathrm{Rp}$ \\
\hline Inisiasi (SIUP) & $\mathrm{Rp} 2.775 .143$ \\
\hline TOTAL & $\mathrm{Rp}$ \\
\hline
\end{tabular}

\section{Aspek finasial}

Pada penelitian ini, terdapat beberapa komponen yang mempengaruhi keadaan finansial. Antara lain biaya investasi, biaya listrik, biaya bahan baku penlolng, biaya perencanaan SDM, biaya operasional, pendapatan, laba rugi, aliran kash dan neraca. Komponen-komponen tersebut lalu diolah untuk menghitung nilai NPV, PBP, IRR dan BCR.

Proyeksi keuangan ditetapkan selama 4 tahun.

- $\quad$ NPV : Rp 95.516.306

- $P B P: 4.2$

- $\quad$ IRR : $27.67 \%$

- $\quad$ BCR : 1,161

Masing-masing angka pada keempat nilai tersebut menunjukan bahwa bisnis kawasan street food ini layak.

4. Analisis Sensitivitas

Analisis sensitivitas yang dilakukan pada penilitain ini adalah dengan mengubah biaya sewa, mengingat pendapatan sewa dapat mengalami perubahan sesuai dengan permintaan dan kondisi pasar. hal tersebut terbukti memiliki pengaruh yang cukup besar, dengan kata lain bisnis penyewaan lahan street food ini sangat sensitive terhadap perubahan harga sewa dikarenakan pendapatan parkir yang juga memiliki pengaruh besar mencapai $7.45 \%$.

5. Analisis Risiko

Risiko yang diteliti dalam penilitian ini adalah risiko pasar, risiko finansial, dan risiko 
operasional. Dari berbagai risiko yang mengancam, risiko operasional memiliki dampak paling besar dan hanya dapat diselesaikan dengan pengawasan terhadap makanan dan minuman yang akan dijual, dengan menjalin kerja sama dengan pemerintah atau BPOM setempat.

\section{KESIMPULAN}

Penelitian ini menghasilkan kesimpulan berupa penilaian kelayakan investasi. Kelayakn investasi berupa nilai NPV $>0$, Nilai IRR $>$ MARR, dan PBP selama 4,2 Tahun. Dengan kebutuhan dana sebesar Rp 218.872.393, didapatkan nilai NPV sebesar Rp 95.516.306, nilai IRR 27,67\% dan PBP selama 4,2 tahun. Dari hasil perhitungan, dapat dikatakan bahwa bisnis penyewaan lahan street food ini layak untuk dijalankan.

\section{REKOMENDASI}

Saran untuk pemilik anatara lain.

a. Pemilik menambah jumlah tenant, agar dapat meningkatkan pendapatan.

b. Pemilik berkolaborasi dengan perusahaan teknologi finansial, agar pengalaman berbelanja konsumen dapat lebih baik, dan keungan lebih teratur.

c. Bekerja sama dengan organisasi penyelenggara acara-acara tertentu sehingga agar nantinya kawasan tersebut dapat dipergunakan untuk event-event tertentu, hal tersebut dapat menarik perhatian konsumen.

\section{DAFTAR PUSTAKA}

Kasmir \& Jakfar 2006, Studi Kelayakan Bisnis . Jakarta, Kencana Prenada Media Group.

Siregar, B 1991. Analisis Kelayakan Pabrik. Bandung, Institut Teknologi Bandung.

Lazuardi, R, Fitria, L \& Bakar, A 2018, 'Artikel Jurnal IImiah Analisis Kelayakan Usaha Mobile Carwash di Kota Bandung', vol.1, No. 3, hh. 48-56.

Umar,Husein (2007). Studi Kelayakan Bisnis Edisi ketiga revisi. Jakarta: PT Gramedia Pustaka Utama.

Umar,Husein 2007. Studi Kelayakan Bisnis Edisi ketiga revisi. Jakarta, PT Gramedia Pustaka Utama.
Mudjiarto dan Aliaras Wahid. (2006). Membangun Karakter dan Kepribadian Kewirausahaan. Yogyakarta: Graha Ilmu.

Putra, Rizky Sanjaya (2016). Analisis kelayakan Usaha Gerabah Anggota Koperasi Kasongan Usaha Bersama (KUB). Yogyakarta : Universitas Negeri Yogyakarta.

Horne Van C. James. (2004). Prinsip-Prinsip Manajemen Keuangan. Edisi Kesembilan. Jakarta: Salemba Empat

Umar, Husein. (2001). Study Kelayakan Bisnis Edisi 3 Revisi. Jakarta : Gramedia Pustaka Utama.

Badan Pusat Statidtik (2017). Statistik Pemuda Indonesia, Jakarta : BPS

Alimi, Buliyaminu Adegbemiro 2016, Risk factors in street food practices in developing countries: $A$ Review, Elsevier, Beijing.

Ishak, N, Aziz, K, Amri, A 2010, Dynamism of a night market, Universiti Tun Abdul Razak, Malaysia.

Lee, S, Chang, S, Hou, J, Lin, C 2008 International Journal of Culture, Tourism and Hospitality Research Vol. 2 No. 3, pp. 217-233, Emerald, Taiwan.

Obi, J, Stephen, A, Talulope, A, Olokundun, M, Amaihian, A, Borishade, T, \& Fred, P 2018, Contribution of small and medium entreprises to economic development: Evidence from a transiting economy, vol.1, No. 1,hh. 835-839. Elsevier, Nigeria. 